\title{
ANALISIS TEKNIK PENERJEMAHAN DAN KUALITAS TERJEMAHAN KALIMAT YANG MENGANDUNG UNGKAPAN SATIRE DALAM NOVEL THE 100-YEAR-OLD MAN WHO CLIMBED OUT OF THE WINDOW AND DISSAPEARED
}

\author{
Ambhita Dhyaningrum ${ }^{1}$, M. R. Nababan', Djatmika ${ }^{3}$ \\ ${ }^{1}$ Universitas Sebelas Maret, Surakarta, Indonesia \\ ${ }^{2}$ Professor at Universitas Sebelas Maret, Surakarta, Indonesia \\ ${ }^{3}$ Professor in Linguistics at Universitas Sebelas Maret, Surakarta, Indonesia \\ dee_ambhita@yahoo.com
}

\begin{abstract}
Satire is a part of language style, a figure of speech used to mock, critize, or ridicule. The language style exists in a novel by Jonas Jonasson, The 100-Year-Old Man who Climbed Out of the Window and Dissapeared. The aims of this research are to find out the complexity of sentences containing satirical expression, types of satirical expression, rhetorical devices in satirical expression, techniques of translation, and the impact of translation techniques to the quality of translation of sentences containing satirical expression in the novel.

This research is a translation study with descriptive qualitative method and single embedded case. The data of research are all sentences containing satirical expression and their translation. This research applies document analysis, questioner, and focus group discussion as the data collecting method. This research also applies Spradley's ethnographic method as the data analysis technique.

The construction of sentences containing satirical expression in this research consist of complex sentences (65 cases or 36,72\%), simple sentences (41 cases or $23,16 \%$ ), compound sentenses (35 cases or 19,77\%), compound-complex sentences (32 cases or $18,08 \%$ ), and minor sentences (4 cases or 2,26\%). The types of satirical expression consist of personal (67 cases or 37,86\%), episodic (62 cases or $35,03 \%$ ), experential (40 cases or $22,60 \%$ ), and textual (8 cases or 4,52 $\%)$. The most frequent rhetorical devices in the satirical expressions are irony (47 cases or $26,55 \%$ ), ridicule ( 45 cases or $25,42 \%$ ), and sarcasm ( 24 cases or 13,56 $\%)$. The translation techniques which has the highest frequency are establihed equivalent (787 cases or 47,30\%), linguistic compression (170 cases or 10,22\%), pure borrowing (130 cases or 7,81\%), transposition (98 cases or 5,89\%), and reduction (92 cases or $5,53 \%)$. The most frequent translation techniques give positive contribution to the whole of translation quality. From the assesment of three aspects of quality, it can be concluded that the translator is capable enough to apply the translation techniques. There is positive impact of the techinques applied and the total quality of translation. The average score of translation quality is 2,82 , which can be categorized as high.
\end{abstract}

Keywords: translation, satire, rhetorical devices, translation technique, translation quality. 


\section{PENDAHULUAN}

Gaya bahasa adalah cara mengungkapkan pikiran melalui bahasa secara khas yang memperlihatkan jiwa dan kepribadian penulis atau pemakai bahasa (Keraf, 2009: 113). Dengan menggunakan gaya bahasa tertentu, seorang penulis dapat meningkatkan estetika karyanya, sekaligus menunjukkan kekhasan caranya dalam menyajikan karya. Penggunaan gaya bahasa akan makin memperindah suatu karya dan memikat orang yang membacanya. Ratna (2014: 151) menyatakan bahwa dalam gaya bahasa, kata-kata selain memiliki arti tertentu juga berfungsi untuk mengevokasi bahkan mengernegisasikan kata-kata lain, demikian seterusnya sehingga keseluruhan aspek berfungsi secara maksimal.

Menerjemahkan bukan sekadar mengalihbahasakan teks dari bahasa sumber ke bahasa sasaran. Skill menerjemahkan yang baik juga tak lepas dari kemahiran penerjemah untuk mengalihkan makna dan unsur estetikanya-termasuk dalam hal ini adalah gaya bahasa. Nida dan Taber (1982: 12) menyatakan bahwa, "Translating consist of reproducing in the receptor language natural equivalent of the source language message, first in terms of message and secondly in term of style". Dari pernyataan Nida dan Taber, terdapat dua hal di dalam proses penerjemahan. Yang pertama adalah menghasilkan pesan yang sepadan dengan bahasa sumber, dan yang kedua adalah menghasilkan kesepadanan yang alamiah dalam hal gaya. Namun, penerjemahan dalam hal gaya adalah sesuatu yang rumit. Nababan (2008:59) menyatakan bahwa kompleksitas stilistik merupakan salah satu faktor penyebab sulitnya penerjemahan dilakukan.

Dalam proses penerjemahan, penerjemah sering kali menjumpai persoalan. Teknik penerjemahan diperlukan untuk memecahkan berbagai persoalan tersebut. 
Teknik penerjemahan adalah cara yang digunakan untuk mengalihkan pesan dari BSu ke BSa, diterapkan pada tataran kata, frasa, klausa maupun kalimat. Menurut Molina dan Albir (2002), teknik penerjemahan memiliki lima karakteristik yaitu 1) memengaruhi hasil terjemahan, 2) diklasifikasikan dengan perbandingan pada teks Bsu, 3) berada pada tataran mikro, 4) tidak saling berkaitan tetapi berdasarkan konteks tertentu, dan 5) bersifat fungsional.

Penggunaan teknik-teknik penerjemahan akan membantu penerjemah dalam menentukan bentuk dan struktur kata, frasa, klausa, serta kalimat terjemahannya. Selain, itu penerjemah juga akan terbantu dalam menentukan padanan yang paling tepat di dalam bahasa sasaran. Dengan demikian, kesepadanan terjemahan dapat diterapkan dalam berbagai satuan lingual. Selain itu, penggunaan teknik penerjemahan tidak hanya akan menghasilkan terjemahan yang akurat tetapi juga berterima dan mudah dibaca oleh pembaca teks sasaran. Kedelapanbelas teknik yang dikemukakan oleh Molina dan Albir (2002) tersebut adalah adaptasi, amplifikasi, peminjaman, kalke, kompensasi, deskripsi, kreasi diskursif, padanan lazim, generalisasi, amplifikasi linguistik, kompresi linguistik, penerjemahan harfiah, modulasi, partikularisasi, reduksi, substitusi, transposisi, dan variasi.

Penilaian terhadap kualitas penerjemahan sangat relevan diterapkan pada empat bidang yaitu 1) bidang terjemahan yang dipublikasikan, 2) bidang terjemahan profesional, 3) bidang terjemahan yang dihasilkan dalam konteks pengajaran mata kuliah praktik penerjemahan, dan 4) bidang terjemahan yang dikaji dalam konteks penelitian penerjemahan (Nababan dkk: 2012).

Penilaian terhadap suatu karya terjemahan bertujuan untuk mengetahui sejauh mana kekuatan dan kelemahan terjemahan. Penilaian terhadap karya terjemahan berupa 
karya yang dipublikasikan—dalam hal ini buku—akan bermanfaat bagi penerjemah, penerbit, dan pembaca. Untuk penerjemah, penilaian terjemahan akan memberikan evaluasi dan masukan kepadanya yang akan berguna untuk perbaikan di masa yang akan datang. Bagi penerbit, adanya penilaian terjemahan akan memberikan masukan tentang mutu buku terjemahan yang mereka terbitkan. Dengan demikian penerbit juga akan melakukan upaya perbaikan terhadap mutu buku-buku terjemahannya di masa mendatang. Para pembaca juga akan mendapatkan keuntungan dengan adanya kritik tentang mutu terjemahan suatu buku. Dengan demikian, tidak sia-sia mereka mengeluarkan uang untuk membeli buku terjemahan.

Para pakar teori penerjemahan sependapat bahwa suatu tek sterjemahan dapat dikatakan berkualitas baik jika: 1) teks terjemahan tersebut akurat dari segi isinya (dengan kata lain, pesan yang terkandung dalam teks terjemahan harus sama dengan pesan yang terkandung dalam teks asli atau teks sumber), 2) teks terjemahan diungkapkan dengan kaidah-kaidah yang berlaku dalam bahasa sasaran dan tidak bertentangan dengan norma dan budaya yang berlaku dalam bahasa sasaran, dan 3) teks terjemahan dapat dipahami dengan mudah oleh pembaca sasaran (Nababan dkk.: 2012). Ketiga parameter untuk mengukur kualitas terjemahan itu dijabarkan sebagai keakuratan (accuracy), keberterimaan (acceptability), dan keterbacaan (readibility). Menurut Nababan dkk. (2012: 44), keakuratan merupakan istilah yang digunakan dalam pengevaluasian terjemahan untuk merujuk apakah teks bahasa sumber dan teks bahasa sasaran sudah sepadan atau belum. Istilah keberterimaan merujuk pada apakah suatu terjemahan sudah diungkapkan sesuai dengan kaidah-kaidah, norma dan budaya yang berlaku dalam bahasa sasaran ataukah belum, baik pada tataran mikro maupun pada tataran makro (Nababan dkk., 2012: 44-45). Sementara itu, aspek keterbacaan merujuk 
pada mudah atau sukarnya suatu teks terjemahan dipahami. dalam konteks penerjemahan, istilah keterbacaan pada dasarnya tidak hanya menyangkut keterbacaan teks bahasa sumber tetapi juga keterbacaan teks bahasa sasaran (Nababan dkk., 2012: 45)

Kalimat adalah kelompok kata yang mengandung gagasan, pesan, atau informasi yang paling sedikit terdiri atas subjek dan predikat. Berry (2013: 54) lebih jauh menyatakan bahwa kalimat adalah " $a$ string of words that follows the rules for forming clauses and combinations of clauses." Kalimat merupakan jalinan kata yang memenuhi aturan pembentukan klausa dan kombinasi klausa. pembagian kompleksitas kalimat dapat dijabarkan menjadi: 1) minor sentence, atau kalimat minor, adalah kalimat yang sebagian unsurnya hilang. Dapat berupa fragmen maupun non-kalimat; 2) major sentence, atau kalimat mayor, adalah kalimat yang bagian-bagiannya utuh. Terdiri atas: simple sentence (kalimat yang terdiri atas satu klausa independen) dan multiple sentence atau kalimat majemuk, terdiri atas kombinasi dua atau lebih klausa. Kalimat majemuk dibagi menjadi dua yaitu a) compound sentence atau kalimat majemuk setara, dengan kombinasi klausa koordinatif (konjungsi yang digunakan adalah and, but, dan or); b) complex sentence atau kalimat majemuk bertingkat, dengan kombinasi klausa subordinatif (konjungsi yang digunakan adalah when, if, although, since, before, as soon as, so that); dan c) compound-comples sentence atau kalimat majemuk campuran, menggunakan klausa koordinatif dan subordinatif.

Satire dapat ditinjau dari tataran makro dan mikro. Dari tataran makro, satire adalah jenis karangan, sedangkan dalam tataran mikro, satire adalah gaya bahasa, tepatnya majas. Satire sebagai jenis karangan, menurut Stanton (2009:131) adalah karikatur versi sastra karena cenderung melebih-lebihkan, cerdas, sekaligus ironis. 
Satire mengekspos absurditas manusia atau institusi, membongkar kesenjangan antara topeng dan wajah sebenarnya. Contoh satire adalah Gulliver's Travel karya Jonathan Swift yang berisi penghinaan terhadap Inggris dan seluruh umat manusia, Babbit karya Lewis yang menyerang pebisnis berkebangsaan Amerika, dan Catch 22 karya Heller yang menyerang Angkatan Udara Amerika.

Satire sebagai gaya bahasa, tepatnya majas, didefiniskan oleh Keraf (2010:144) sebagai ungkapan yang menertawakan atau menolak sesuatu. Wicaksono (2014:44) menyatakan bahwa satire merupakan ungkapan yang menggunakan sarkasme, ironi, atau parodi, untuk mengancam atau menertawakan gagasan, kebiasaan, dan lain-lain.

Menurut Simpson (2003: 71), target satire dibedakan menjadi empat, yaitu episodic, personal, experential, dan textual. Satire episodic, adalah satire yang targetnya berupa kondisi, tindakan, atau peristiwa khusus yang terjadi di ranah masyarakat. Satire personal adalah satire yang targetnya adalah individu tertentu, ditujukan pada kepribadian seseorang terutama sifat stereotipe dan arketipe perilaku manusia. Satire experential adalah satire satire yang targetnya adalah aspek kondisi dan pengalaman manusia yang bersifat menetap, sebagai lawan dari episode dan peristiwa tertentu. Satire textual adalah satire yang targetnya adalah kode linguistik sebagai objek yang diserang.

Penulis novel The 100-Year-Old Man who Climbed Out of the Window and Dissapeared menggunakan berbagai cara untuk mengungkapkan satire, yaitu dengan menggunakan berbagai peranti retoris.

Rao (2004) menggunakan istilah "metode" untuk menyatakan peranti yang digunakan oleh penulis dalam menulis satire. Menurutnya, "Satiric methods include irony, sarcasm, invective, innuendo, burlesque, parody, ridiculous, exaggeration, wit, humor, farce". Sementara itu, Gaughen (2016) mencatat berbagai peranti retoris yang 
digunakan dalam satire, yaitu ironi, travesty, burlesque, parodi, farce, invective, knaves \& fools, malapropisme, ridicule, serta peranti berupa perbandingan yang mengandung incongruity seperti metafor dan oksimoron.

Dari kedua pendapat tersebut, penulis merumuskan bahwa peranto retoris yang terdapat dalam satire adalah: 1) Ironi, yaitu pernyataan yang kata-katanya mengandung maksud yang bertolak belakang; 2) invective, adalah penggunaan kata-kata kasar atau memaki terhadap seseorang maupun kondisi; 3) inuendo, adalah pernyataan secara tidak langsung atau sindiran halus terhadap kesalahan seseorang atau kondisi, atau karakter yang buruk 4) burlesque, merupakan ungkapan yang bersifat konyol dan melebihlebihkan; 4) parodi, yaitu ejekan atau olok-olok dengan meniru atau mengubah bentuk suatu karya yang serius, 5) ridicule, adalah ucapan atau tindakan yangdimaksudkan untuk menimbulkan tawa meremehkan atau olok-olok; 5) exaggeration, adalah pernyataan melebih-lebihkan suatu fakta (Rao: 2004). Dalam penelitian ini, peneliti akan menggunakan istilah hiperbola; 6) malapropisme, salah melafalkan nama atau sesuatu dengan sengaja, dengan tujuan untuk mengolok-olok; 7) travesty, yaitu pernyataan yang mengolok-olok sesuatu yang bersifat serius (biasanya agama) sampai tingkat yang rendah; 8) farce, adalah situasi yang dilebih-lebihkan hingga mustahil, untuk memancing tawa. Biasanya terdapat dalam komedi tingkat rendah; adegan pertengkaran, perkelahian, kekurangajaran, permainan kasar, nyanyian yang berisik, tindakan brutal, tipu muslihat, tingkah yang konyol, tingkah orang mabuk, slapstick; 9) metafora, merupakan analogi yang membandingkan dua hal secara langsung tetapi dalam bentuk singkat; 10) oksimoron, yaitu pernyataan yang berusaha menggabungkan kata-kata untuk mencapai efek bertentangan. 


\section{TEORI DAN METODOLOGI}

\section{Lokasi Penelitian}

Lokasi penelitian merupakan "focus-determined boundary", yang secara harafiah berarti 'batas yang ditentukan oleh fokus atau objek penelitian' (Lincoln dan Guba, 1985 dalam Santosa, 2014: 47). Sementara itu, menurut Spradley dalam Santosa (2014: 40), lokasi penelitian harus memiliki unsur-unsur pokok dari lokasi penelitian yaitu tempat atau seting, aktor atau partisipan, dan kejadian.

Lokasi penelitan ini adalah novel yang berjudul The 100-Year-Old Man who Climbed Out of the Window and Dissapeared yang ditulis oleh Jonas Jonasson, diterbitkan pertama kali oleh Piratförlaget, Swedia, dan diterjemahkan dalam Bahasa Indonesia oleh Bentang Pustaka. Novel ini ber-setting di Swedia, tepatnya di kota kecil bernama Malmköping. Di sanalah, di sebuah rumah lansia, cerita pertama kali bermula. Dari sini, dikisahkan tokoh utama, Allan Karlson, bertualang ke berbagai belahan dunia dengan keahliannya sebagai ahli peledak. Setting tempat terus berpindah-pindah, dari Malmköping ke Strängnas, Brynge, Hällefornsnäs (Spanyol), New York, Tibet, Korea Utara, hingga Bali (Indonesia).

Partisipan dalam penelitian ini adalah semua tokoh yang ada dalam The 100Year-Old Man who Climbed Out of the Window and Dissapeared, terutama tokoh utamanya-Allan Karlson. Tokoh-tokoh lain dalam novel ini adalah Julius Jonsson, Benny, Gunilla (Jelita), Direktur Alice, dan Ni Wayan Laksmi.

Kejadian yang diangkat dalam novel The 100-Year-Old Man who Climbed Out of the Window and Dissapeared adalah semua kalimat yang mengandung ungkapan satire yang terdapat di dalam novel tersebut. 


\section{Data dan Sumber Data}

Data yang dikaji di dalam penelitian ini dibagi menjadi data primer dan data sekunder. Yang termasuk data primer adalah: 1) data lingusitik, yaitu semua data yang termasuk dalam ungkapan satire di dalam novel The 100-Year-Old Man who Climbed Out of the Window and Dissapeared dan terjemahannya dalam bahasa Indonesia, dan 2) data informan, yaitu hasil kuesioner dan focus group discussion dari para rater tentang keakuratan, keberterimaan, dan keterbacaan. Sementara itu, data sekunder dalam penelitian ini adalah segala informasi yang terkait dengan novel The 100-Year-Old Man who Climbed Out of the Window and Dissapeared.

\section{Sampling}

Karena penelitian ini bersifat kualitatif deskriptif, dipilih sumber data yang mewakili informasi yang diperlukan. Oleh karena itu, pemilihan sampel berdasarkan kriteria digunakan sebagai dasar pemilihan data dalam novel serta informan dalam penelitian ini. Kriteria dalam pemilihan data adalah semua kalimat yang mengandung sindiran, ejekan, maupun olok-olok dalam hal kelemahan manusia, budaya, kondisi sosial, maupun politik. Teknik sampling yang ditujukan kepada para informan ditentukan secara selektif karena yang diutamakan adalah kedalaman, kemantapan, serta ketuntasan informasinya. Oleh karena itulah, informan yang dipilih adalah ahli dalam bidangnya, yang memiliki kompetensi memadai dalam memberikan penilaian terhadap teks terjemahan. Informan terdiri atas 3 orang rater dalam aspek keakuratan dan keberterimaan, dan 3 orang rater dalam aspek keterbacaan (responden). Kriteria rater dalam aspek keakuratan dan keberterimaan adalah 1) menguasai bahasa Inggris (BSu) dan bahasa Indonesia (Bsa) dengan baik; 2) memiliki latar belakang pendidikan penerjemahan, minimal S2 Penerjemahan; 3) memiliki pengetahuan dan pengalaman 
dalam bidang penerjemahan; dan 4) bersedia menjadi rater dan membantu memberikan kontribusi terhadap penelitian ini. Sementara itu, kriteria rater dalam aspek keterbacaan (responden) adalah: 1) menguasai Bahasa Indonesia dengan baik, 2) memiliki latar belakang pendidikan minimal S1,3) suka membaca buku, terutama novel terjemahan; dan 4) bersedia menjadi rater serta membantu memberikan kontribusi terhadap penelitian ini.

\section{Teknik Pemerolehan Data}

Pemerolehan data dilakukan dengan cara analisis ini (content analysis), yang merupakan variasi bentuk dari analisis dokumen. Dalam pelaksanaannya, analisis isi dalam penelitian ini dilakukan dengan 1) membaca novel The 100-Year-Old Man who Climbed Out of the Window and Dissapeared, baik novel asli maupun terjemahannya, serta memahami konteks situasi dalam novel tersebut; 2) mengumpulkan dan mengklasifikasikan kalimat yang mengandung ungkapan satire yang ditemukan dalam novel The 100-Year-Old Man who Climbed Out of the Window and Dissapeared; 3) memberikan kode data; 4) menganalisis teknik penerjemahan yang digunakan dalam menerjemahkan ungkapan satire di dalam novel tersebut; dan 5) menganalisis pengaruh penerapan teknik penerjemahan terhadap kualitas terjemahan.

Kuesioner digunakan untuk mengumpulkan data sekunder agar diperoleh informasi yang dapat menjadi pertimbangan dalam melakukan analisis. Dalam penelitian ini, kuesioner bertujuan untuk memperoleh data tentang tingkat keakuratan, keberterimaan, serta keterbacaan. Informasi diperoleh dengan cara memberikan kuesioner pada kepada rater. Kuesioner berisi pertanyaan-pertanyaan yang bersifat tertutup dengan pilihan jawaban yang sudah dibatasi. Dalam kuesioner juga tersedia 
kolom komentar agar rater dapat memberikan pendapatnya. Kuesioneryang telah diisi oleh para rater akan didiskusikan lebih lanjut dalam FGD untuk disepakati hasilnya.

Sebagai tindak lanjut kuesioner, diadakan sebuah forum diskusi untuk membahas bersama tentang hasil kuesioner. FGD dilakukan untuk memperoleh kemantapan data. Di dalam forum diskusi ini, penilaian terhadap kualitas terjemahan didiskusikan dan disepakati bersama hasilnya.

\section{Teknik Analisis Data}

Teknik analisis data dalam penelitian ini menggunakan teori Spradley tentang analisis domain, taksonomi, dan komponensial. Analisis domain dilakukan untuk memilah antara yang data dan bukan data. Kalimat yang mengandung ungkapan satire dalam novel The 100-Year-Old Man who Climbed Out of the Window and Dissapeared adalah data, dan selain itu bukan data.

Jika analisis domain memberikan hasil yang luas dan umum, analisis taksonomi dilakukan untuk memperdalam pengumpulan data, yaitu dengan cara mengklasifikasikan data berdasarkan kategorinya. Setelah itu, dilakukan analisis komponensial untuk menghubungkan hubungan antarklasifikasi data dengan kualitas terjemahannya. Pada tahap ini, tingkat keakuratan dan keberterimaan dikaitkan dengan kompleksitas kalimat yang mengandung ungkapan satire, tipe satire, peranti retoris pengungkap satire, dan teknik penerjemahan, serta kualitas terjemahan.

\section{TEMUAN DAN PEMBAHASAN}

Setelah Penulis melakukan analisis, berikut adalah temuan-temuan yang dihasilkan. Dari segi kompleksitas kalimat, berikut adalah tabel yang menunjukkan temuannya. 
Tabel 4.1. Kompleksitas Kalimat yang Mengandung Ungkapan Satire

\begin{tabular}{|c|l|c|c|}
\hline No & \multicolumn{1}{|c|}{ Jenis Kalimat } & $\sum$ & \% \\
\hline 1 & Kalimat Minor (KMin) & 4 & $2,26 \%$ \\
\hline 2 & Kalimat Tunggal (KT) & 41 & $23,16 \%$ \\
\hline 3 & Kalimat Majemuk Setara (KMS) & 35 & $19,77 \%$ \\
\hline 4 & Kalimat Majemuk Bertingkat (KMB) & 65 & $36,72 \%$ \\
\hline 5 & Kalimat Majemuk Campuran (KMC) & 32 & $18,08 \%$ \\
\hline \multicolumn{2}{|c|}{ Total } & $\mathbf{1 7 7}$ & $\mathbf{1 0 0} \%$ \\
\hline
\end{tabular}

Untuk meneliti gaya bahasa penulis, perlu ditelusuri bagaimana ia membangun kalimat-kalimatnya dalam sebuah teks. Penelitian ini juga melakukan analisis terhadap bangun kalimat yang digunakan oleh penulis, dan bagaimana penerjemah merekonstruksinya dalam teks bahasa sasaran. Hal ini dikarenakan, konstruksi kalimat pada bahasa sasaran sangat berpengaruh pada kualitas terjemahan, terutama dalam aspek keterbacaan. Apabila konstruksi kalimat pada teks bahasa sumber sangat kompleks dan dibiarkan begitu saja dalam teks bahasa sasaran, sangat memungkinkan untuk membuat keterbacaan menjadi rendah. Pembaca akan kesulitan dalam memahaminya. Oleh karena itu, kepekaan penerjemah juga diperlukan ketika menghadapinya. Apakah sebuah kalimat dalam teks BSa harus dialihkan dalam bahasa sasaran dengan mempertahankan struktur aslinya, atau harus diubah bangun kalimatnya demi kepentingan keterbacaan terjemahan.

Hasil analisis data tentang jumlah dan persentase tipe satire berdasarkan target yang ditujunya dapat dilihat pada tabel berikut ini.

Tabel 4.2. Tipe Satire berdasarkan Target yang Dituju

\begin{tabular}{|l|l|c|c|}
\hline No & Tipe satire & $\sum$ & $\%$ \\
\hline $\mathbf{1}$ & Personal & 67 & $35,03 \%$ \\
\hline $\mathbf{2}$ & Episodic & 62 & $37,86 \%$ \\
\hline $\mathbf{3}$ & Experential & 40 & $22,60 \%$ \\
\hline $\mathbf{4}$ & Textual & 8 & $4,52 \%$ \\
\hline \multicolumn{2}{|c|}{ Total } & 177 & $100 \%$ \\
\hline
\end{tabular}


Ada berbagai aspek yang terkandung dalam keempat tipe ungkapan satire. Dalam episodic satire, tardapat ungkapan yang mengolok-olok peristiwa atau kejadian yang terjadi di ranah publik antara lain dalam aspek sosial kemasyarakatan, politik, maupun agama. Dalam personal satire terdapat aspek sifat, kondisi, dan perilaku seseorang. Dalam experential satire terdapat aspek pengalaman hidup. Dalam textual lebih beragam, karena ungkapan tipe ini dapat digunakan untuk menyerang dalam aspek agama, politik, budaya, dan yang lainnya.

Tabel 4.3. Rekapitulasi Peranti Retoris

\begin{tabular}{|c|l|c|c|}
\hline No & $\begin{array}{c}\text { Peranti } \\
\text { retoris }\end{array}$ & $\sum$ & $\%$ \\
\hline 1 & Ironi & 47 & $25,99 \%$ \\
\hline 2 & Ridicule & 35 & $19,77 \%$ \\
\hline 3 & Sarkasme & 24 & $13,56 \%$ \\
\hline 4 & Inuendo & 16 & $9,04 \%$ \\
\hline 5 & Hiperbola & 13 & $7,34 \%$ \\
\hline 6 & Alusio & 9 & $5,08 \%$ \\
\hline 7 & Paradoks & 7 & $3,95 \%$ \\
\hline 8 & Oksimoron & 5 & $2,82 \%$ \\
\hline 9 & Kontradiksio & 5 & $2,82 \%$ \\
\hline 10 & Burlesque & 4 & $2,26 \%$ \\
\hline 11 & Invective & 3 & $1,69 \%$ \\
\hline 12 & Parodi & 1 & $0,56 \%$ \\
\hline 13 & Malapropism & 3 & $1,69 \%$ \\
\hline 14 & Travesty & 1 & $0,56 \%$ \\
\hline 15 & Farce & 2 & $1,13 \%$ \\
\hline 16 & Metonimia & 2 & $1,13 \%$ \\
\hline Total & 177 & $100 \%$ \\
\hline
\end{tabular}

Dari tabel di atas, dapat diketahui bahwa peranti retoris yang paling sering digunakan dalam kalimat yang mengandung ungkapan satire adalah ironi yang mencapai 47 atau 25,99 \%, disusul kemudian oleh ridicule sebanyak 35 atau 19,77\%, dan sarkasme sebanyak 24 atau 13,56 \%. Ini artinya, kalimat yang mengandung ungkapan satire dalam penelitian ini lebih cenderung memakai sindrian yang bertolak 
belakang dengan kenyataan yang ada (ironi) menggunakan ungkapan yang memancing tawa mengejek atau meremehkan (ridicule); dan penggunaan kata-kata kasar (sarkasme).

Jika dilihat dari hubungan antara tipe satire dan peranti retoris yang digunakannya, dalam episodic satire, peranti retoris yang paling banyak digunakan adalah ironi; dalam personal satire, peranti retoris yang paling banyak digunakan adalah sarkasme; dalam experential satire, peranti retoris yang paling banyak digunakan adalah ironi; sementara peranti retoris adalah ironi dan ridicule.

Permasalahan penelitian yang keempat adalah teknik penerjemahan. Peneliti mengidentifikasi teknik-teknik penerjemahan yang digunakan penerjemah dalam memindahkan ungkapan satire dari bahasa sumber ke dalam bahasa sasaran. Hasil analisis terhadap 177 data, ditemukan bahwa teknik yang paling banyak digunakan adalah kesepadanan lazim sebanyak 787 data (47,30 \%), kompresi linguistik sebanyak 170 data $(10,22 \%)$, peminjaman murni sebanyak 130 (7,81\%). Hasil selengkapnya dapat dilihat dalam tabel berikut ini.

Tabel 4.3. Teknik Penerjemahan

\begin{tabular}{|c|l|c|c|}
\hline No & \multicolumn{1}{|c|}{ Teknik Penerjemahan } & $\sum$ & $\%$ \\
\hline 1 & Kesepadanan lazim & 787 & $47,30 \%$ \\
\hline 2 & Kompresi linguistik & 170 & $10,22 \%$ \\
\hline 3 & Peminjaman murni & 130 & $7,81 \%$ \\
\hline 4 & Transposisi & 98 & $5,89 \%$ \\
\hline 5 & Reduksi & 92 & $5,53 \%$ \\
\hline 6 & Amplifikasi & 89 & $5,35 \%$ \\
\hline 7 & Amplifikasi linguistik & 52 & $3,13 \%$ \\
\hline 8 & Modulasi & 38 & $2,28 \%$ \\
\hline 9 & Kompensasi & 25 & $1,50 \%$ \\
\hline 10 & Peminjaman naturalisasi & 24 & $1,44 \%$ \\
\hline 11 & Kalke & 23 & $1,38 \%$ \\
\hline 12 & Harfiah & 18 & $1,08 \%$ \\
\hline
\end{tabular}




\begin{tabular}{|c|l|c|c|}
\hline No & \multicolumn{1}{|c|}{ Teknik Penerjemahan } & $\sum$ & \% \\
\hline 13 & Kreasi diskursif & 14 & $0,84 \%$ \\
\hline 14 & Partikularisasi & 9 & $0,54 \%$ \\
\hline 15 & Variasi & 7 & $0,42 \%$ \\
\hline 16 & Adaptasi & 4 & $0,24 \%$ \\
\hline 17 & Generalisasi & 2 & $4,99 \%$ \\
\hline 18 & Deskripsi & 1 & $0,06 \%$ \\
\hline \multicolumn{2}{|c|}{ Total } & $\mathbf{1 6 6 4}$ & $\mathbf{1 0 0} \%$ \\
\hline
\end{tabular}

Ini menunjukkan bahwa penerjemahan ungkapan satire dilakukan dengan cara memindahkan atau ekspresi yang diterjemahkan telah dikenal baik dalam kamus bahasa sasaran maupun dalam pemakaian sehari-hari. Teknik paling banyak digunakan yang kedua adalah kompresi linguistik. Terjemahan kalimat yang mengandung ungkapan satire banyak dilakukan dengan memadatkan informasi dari bahasa sumber ke bahasa sasaran. Hal ini disebabkan oleh kompleksnya struktur informasi dalam ungkapan satire, sehingga dirasa perlu untuk memadatkannya di dalam bahasa sasaran. Teknik peminjaman murni menduduki posisi ketiga dalam frekuensi penerapannya. Kebanyakan teknik diterjemahkan dalam memindahkan nama tokoh, maupun istilah yang tidak ada padanannya dalam bahasa sasaran. Ini dimaksudkan agar informasi yang terdapat dalam bahasa sasaran diterima dengan akurat tanpa ada distorsi makna. Teknik lain yang digunakan adalah transposisi dan reduksi. Teknik transposisi diperlukan karena sistem bahasa sumber berbeda dengan sistem bahasa sasaran. Adakalanya, teknik transposisi digunakan dengan cara menggeser struktur kalimat dengan memecahnya, karena kalimat dirasa terlalu panjang sehingga akan menimbulkan rendahnya keterbacaan. Sementara itu, teknik reduksi juga banyak digunakan agar kalimat tidak terlalu bertele-tele sehingga tidak nyaman dibaca.

Terjemahan yang berkualitas harus memenuhi tiga aspek, yaitu aspek keakuratan, aspek keberterimaan dan aspek keterbacaan (Nababan dkk: 2012). Ketiga 
aspek ini saling berkaitan. Jika sebuah teks terjemahan memiliki keakuratan tinggi, keberterimaan dan keterbacaan pun akan mengikutinya.

Dari hasil analisis data terjemahan dalam penelitian ini, kualitas terjemahan novel T100YOMWCOOTWAD berada dalam kategori akurat, berterima, keterbacaan tinggi, yaitu dengan skor 2,82. Ini tentu saja tidak lepas dari ketepatan penerapan teknik penerjemahan di dalam menerjemahkan dari bahasa sumber ke bahasa sasaran. Teknikteknik dominan yang berkontribusi positif terhadap keakuratan terjemahan dalam penelitian ini adalah teknik kesepadanan lazim, peminjaman murni, peminjaman naturalisasi, kompresi linguistik, dan transposisi. Teknik yang dominan dalam memengaruhi kekurangakuratan terjemahan adalah kreasi diskursif, reduksi, amplifikasi, dan harfiah. Teknik dominan yang memengaruhi keberterimaan terjemahan adalah teknik kesepadanan lazim, modulasi, kompresi linguistik, adaptasi, dan transposisi. Namun demikian, dengan persentase yang lebih kecil, kreasi diskursif, reduksi, amplifikasi, dan harfiah diterapkan dengan kurang tepat sehingga menghasilkan terjemahan yang kurang berterima. Sementara itu, teknik yang memengaruhi keterbacaan terjemahan antara lain adalah teknik kesepadanan lazim, modulasi, kompresi linguistik, dan transposisi. Dengan persentase yang lebih kecil, teknik kreasi diskursif, reduksi, amplifikasi, dan harfiah mengakibatkan keterbacaan menjadi lebih rendah.

\section{SIMPULAN}

Dari penelitian yang telah dilakukan, dapat diambil simpulan sebagai berikut.

1. Kalimat yang mengandung ungkapan satire direalisasikan dalam kalimat minor hingga kompleks. Gagasan yang sederhana direalisasikan dalam konstruksi 
kalimat yang sederhana seperti kalimat minor dan tunggal, sedangkan gagasan yang lebih kompleks direalisasikan dalam konstruksi kalimat yang kompleks pula, mulai dari kalimat majemuk setara, kalimat majemuk bertingkat, maupun kalimat majemuk setara. Penerjemah harus peka dalam memindahkan konstruksi kalimat pada bahasa sasaran, karena ini akan berdampak terhadap kualitas terjemahan, terutama pada aspek keterbacaan. Penerjemah novel TOHYOMWCOOTWAD cukup berhasil merekonstruksi bangun kalimat ke dalam teks bahasa sasaran, terbukti dari nilai keterbacaan yang cukup tinggi, yaitu 2,71 .

2. Di dalam novel ini, tipe satire yang mendominasi adalah personal, dengan kritik maupun olok-olok lebih banyak ditujukan kepada pribadi seseorang baik dari sifat, kondisi fisik, maupun perilakuknya. Tipe ungkapan satire terbanyak kedua adalah episodic. Di dalam data penelitian, kasus ungkapan satire yang ditujukan pada peristiwa di ranah publik cukup berimbang dengan yang ditujukan kepada pribadi seseorang. Hal ini menunjukkan bahwa kritik maupun olok-olok juga banyak ditujukan pada peristiwa yang terjadi dalam masyarakat baik itu dalam hal budaya maupun kebiasaan masyarakat, maupun peristiwa sosial-politik yang terjadi di ruang publik. Tipe ketiga adalah experential. Dalam tipe ungkapan ini kondisi maupun pengalaman hidup yang bersifat menetap yang mendapat kritik maupun olok-olok. Sementara textual satire juga muncul sebagai olok-olok terhadap teks itu sendiri. Di dalam penelitian ini, data textual satire tidak banyak, namun keberadaannya menunjukkan bahwa dalam novel juga terdapat ungkapan satire yang ditujukan terhadap aspek kebahasaannya. 
3. Peranti retoris yang paling dominan dipakai dalam kalimat yang mengandung ungkapan satire adalah ironi, disusul ridicule dan sarkasme. Jika dikaitkan dengan tipe ungkapan satire, tipe episodic paling banyak menggunakan ironi sebagai peranti retorisnya Pada tipe personal, peranti retoris yang paling dominan digunakan adalah sarkasme. Pada tipe experential, peranti retoris yang paling banyak digunakan adalah ironi. Pada tipe textual, satire diungkap dengan ironi, ridicule, dan malapropisme.

4. Teknik-teknik penerjemahan yang dominan digunakan oleh penerjemah adalah teknik kesepadanan lazim, kompresi linguistik, peminjaman murni, transposisi, dan amplifikasi.

5. Teknik-teknik penerjemahan yang digunakan oleh penerjemah berdampak positif terhadap kualitas terjemahan secara keseluruhan, terbukti dengan skor yang cukup tinggi berdasarkan implementasi pembobotan, yaitu 2,82. Ini artinya penerjemah telah menerapkan teknik dengan baik, meski hasilnya belum sempurna.

\section{SARAN}

\section{Bagi Para Penerjemah}

Agar lebih memerhatikan penerjemahan dalam hal gaya bahasa. Gaya bahasa yang rumit dan sering kali direalisasikan dalam kalimat-kalimat kompleks sehingga membuat keterbacaan menjadi rendah. Penerjemah hendaknya mempertimbangkan teknik penerjemahan yang tepat agar kualitas terjemahan tetap terjaga. Dengan tetap mengedepankan keakuratan dan keberterimaan, keterbacaan juga harus tetap terjaga. 


\section{Bagi Penerbit}

Penerbit sebagai produsen karya-karya terjemahan, hendaknya lebih jeli dalam memantau kualitas terjemahan. Penerbit juga hendaknya menjalin kerja sama dengan para pemerhati terjemahan, atau bahkan dengan pakar terjemahan untuk mendapatkan masukan tentang kualitas terjemahan dari buku-buku yang mereka terbitkan. Dengan demikian, kualitas karya terjemahan yang dihasilkan juga akan meningkat.

\section{Bagi Dunia Akademis}

Penelitian tentang gaya bahasa cukup menarik dan banyak yang masih banyak menyisakan celah untuk dikaji. Dalam hal keakuratan, keberterimaan, serta keterbacaan, sebuah terjemahan dapat dengan lebih objektif diteliti. Akan tetapi dalam hal kesepadanan gaya, merupakan hal yang masih dapat digali, dan parameternya mestinya dapat lebih dikembangkan.

\section{Bagi Para Peneliti Lain}

Penelitian ini menganalisis kompleksitas kalimat, tipe ungkapan sebuah gaya bahasa (satire), peranti retoris yang digunakan, serta teknik penerjemahan dan dampaknya terhadap kualitas terjemahan. Peneliti menyarankan kepada peneliti selanjutnya untuk mengkaji tentang kesepadanan gaya antara teks BSu dan BSa, serta apakah ada pergeseran dalam pemakaian peranti retoris dari teks BSu ke teks BSa dan apakah itu memengaruhi kualitas terjemahan. 


\section{DAFTAR PUSTAKA}

Keraf, Gorys. 2009. Diksi dan Gaya Bahasa. Jakarta: Gramedia Pustaka Utama.

Nida, E.A., Taber, C.R. 1982. The Theory and Practice of Translation. Berlin: E.J. Brills.

Ratna, Prof. Dr. Nyoman Kutha. 2014. Stilistika: Kajian Puitika Bahasa, Sastra, dan Budaya. Yogyakarta: Pustaka Pelajar.

Nababan, M.R. 2008.Teori Menerjemah Bahasa Inggris. Yogyakarta: Pustaka Pelajar.

Nababan, Nuraeni, \&Sumardiono. 2012. "Pengembangan Model Penilaian Kualitas Terjemahan". Jurnal Kajian Linguistik dan Sastra, Vol. 24, No. 1, Juni 2012: 39— 57. Surakarta: Universitas Sebelas Maret.

Rao, T. DurgaSrinivasa. 2004. Problems of Translating Satire from English to Telugu And Vice Versa: An Evaluation. Hyderabad: University of Hyderabad.

Santosa, Riyadi. 2014. Draf Buku Metode Penelitian Kualitatif Kebahasaan. Solo: UNS.

Simpson, Paul. 2004. Stylistic, a Resource Book for Student. New York: Routledge. 2003. On the Discourse of Satire. Amsterdam: John Benjamins B.V.

Sutopo, H.B. 2002.Metodologi Penelitian Kualitatif: Dasar Teori dan Terapannya dalam Penelitian (Qualitative Research Methodology: Basic Theories and their Application to Research). Surakarta: Sebelas Maret University Press. 